\title{
REFLECTIONS AND CONCLUSIONS ON THE WORK DEVELOPED BY THE GROUP OF TEACHING INNOVATION IN ELECTRONICS AT THE UNIVERSITY OF VALLADOLID
}

\author{
Luis Carlos Herrero ${ }^{1}$, Fernando Pardo ${ }^{2}$, María Luisa Fernando ${ }^{1}$, María Luisa González ${ }^{1}$ \\ ${ }^{1}$ School of Industrial Engineering, Universidad de Valladolid, Valladolid, Spain \\ ${ }^{2}$ Schooll of Engineering, Universidad de Santiago de Compostela, Santiago de Compostela, Spain \\ Icherrer@tele.uva.es; marisag@mat.uva.es
}

\begin{abstract}
We hereby present the main conclusions and perspectives obtained by the Group of Teaching Innovation in Electronics (Grupo de Innovación Docente en Electrónica, GIDEN) of the University of Valladolid (UVa) with regard to its main areas of work. This group comprises teachers of the "Specialty in Industrial Electronics" degree, and the degree in Electronic and Automatic Control and Industrial Engineering at the School of Industrial Engineering, who are interested in the introduction of active teaching-learning methodologies. The sharing of ideas, views and conclusions among teachers with common interests in such a cooperative environment has been the driving force behind the success of the different teaching activities carried out by the members of the GIDEN. Such work is presented in this paper.
\end{abstract}

Keywords - Educational innovation, student-centered methodologies, engineering

\section{INTRODUCTION:}

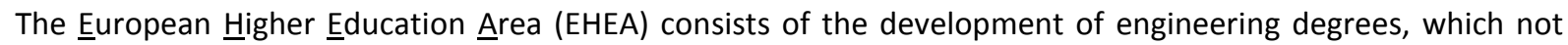
only encompasses the technical and scientific knowledge required to further develop students' professional careers but also covers a series of generic skills which complement student education. Objectives such as continuing study and work, autonomous and team learning, knowledge sharing, etc., have acquired great importance in the adaptation of the courses to the European Credit Transfer System (ECTS). The achievement of these objectives within the framework of the EHEA must be based on the substitution of traditional teaching methods by active teaching-learning methods which allow students to learn, to be active subjects in the classroom and to develop the aforementioned competences for their professional careers. Moreover, such changes should provide teachers with additional tools for assessing levels of knowledge and degrees of skill development so as to determine if students have in fact attained the level required [1,2]. It is important to note that the assessment techniques used in the course had a significant impact on how students address the course $[3,4]$.

In most cases, the traditional method used by teachers is based on their own vision of teaching, their individual tendencies, as well as their lack of knowledge of alternative methods and/or the impossibility of applying them (too many students, classroom's equipment, etc.). This reality is what has led to the conventional lecture format -one of the cheapest methods- as being the most widely used despite the existence of other approaches such as cooperative learning, problem-based learning, project-based learning etc. which have proved to produce better results in students. Even though the effectiveness of these methods has been demonstrated in courses covering different areas [5-7], one of our group objectives was to attain a solid level of coordination among the methodological changes carried out by the teachers within a given course. Moreover, it was decided to implement horizontal coordination (within the same course) and vertical coordination (among the different courses of the degree) by analyzing the different methods that were being 
applied. This was also achieved by way of the assessment techniques used and through the weight that they carried in the final grading of the generic competencies that were being developed. To reach this target, fifteen teachers from the Industrial Technical Engineering degree; "Specialty in Industrial Electronics", from the University of Valladolid (UVa), created the Group of Teaching Innovation in Electronics (Grupo de Innovación Docente en Electrónica, GIDEN) in July 2007. The UVa officially recognized this group on $5^{\text {th }}$ November 2007. The principle lines of work during the last three academic years were:

- To coordinate the activities in the courses of the degree. This created an environment that rationalized the students' workload, facilitating their participation in the learning process.

- To become familiar with and analyze the different teaching methods used in the degree, the type of activities carried out and the way in which such tools were introduced. To promote the application of such new teaching methods. These tasks were developed within the context of the new degree in Electronic and Automatic Industrial Engineering, starting in the academic year 2010-2011.

- To become familiar with and analyze the progress of the assessment methods and criteria used in the degree. This gave rise to an improvement in the assessment of the generic and specific skills developed during the courses.

- To become familiar with and to analyze the generic skills developed in each course, with the aim of:

1. Improving the assessment and formulation of skills.

2. Promoting strategies to develop competence programs and enhance their development.

- To evaluate the innovation processes. This allowed for a mechanism to be established which informed us of the impact of the innovation activities carried out in the degree.

In this paper we present the work developed by the GIDEN and the main conclusions obtained over three academic years; 2007-2008, 2008-2009 and 2009-20010, in the different lines of work in the group. The paper is laid out as follows: Section 2 introduces the coordination activities carried out; Section 3 addresses the teaching methods used in the degree. In Section 4 the activities related to assessment are introduced; Section 5 introduces the activities related to the development of generic competences and lastly, an overall evaluation of the activities is performed and the main conclusions are presented.

\section{COORDINATION OF ACTIVITIES}

The coordination of activities among teachers of the same degree is necessary so that [8]:

- The courses are not considered as independent elements.

- $\quad$ The contents are not repeated (i.e. overlaps are avoided) and are correctly synchronized.

- The students have a homogeneous workload.

- The development of generic competences is balanced.

Taking into account these premises, one of the main objectives of the GIDEN since its onset has been the coordination of course activities. One of the key components, as viewed by the majority of GIDEN's teachers, has been to encourage the continuous work of the students. To reach this objective, teachers had to homogenize and coordinate the proposed activities. Two teachers therefore acted as coordinators, thus developing a dynamic of horizontal coordination. This goal was met by way of requesting that all teachers from the degree fill in a log card with the proposed course activities, indicating the semester week in which the activity was developed and its weight in the final grade. The analysis of these log cards allowed us to detect those weeks in which too much work was concentrated. As a result, through coordination meetings between GIDEN coordinators and the teachers of the degree, and a great deal of effort, the workloads were homogeneously distributed. Once the final plan of activities was obtained, it was published in the classrooms and was indicated that it may experience slight modifications which would be announced well in advance. During the 2009-2010 academic years, "Google Calendar" was introduced to show the schedule of student activities [9]. A specific calendar for the whole degree was set up with the following functionality:

- Teachers could introduce their course activities, indicating their weight in the final grade, and a brief summary of the activity. 
- Teachers and students could see the planned activities of all courses. In this manner, a broad vision of the student workload is provided, thus allowing for its homogeneous distribution and also for the improvement of student planning and organization.

- Teachers could modify and introduce new activities whilst maintaining a homogeneous workload.

The work of course and degree coordinators was easily executed using this tool. In order to determine the student's view of the coordination efforts, they were handed a survey, of which Fig. 1 shows the outcome of the results obtained in the 2007-08, 2008-09 and 2009-10 academic years. From the data gathered in this survey, we can deduce that coordination efforts have been appreciated valued over the years.

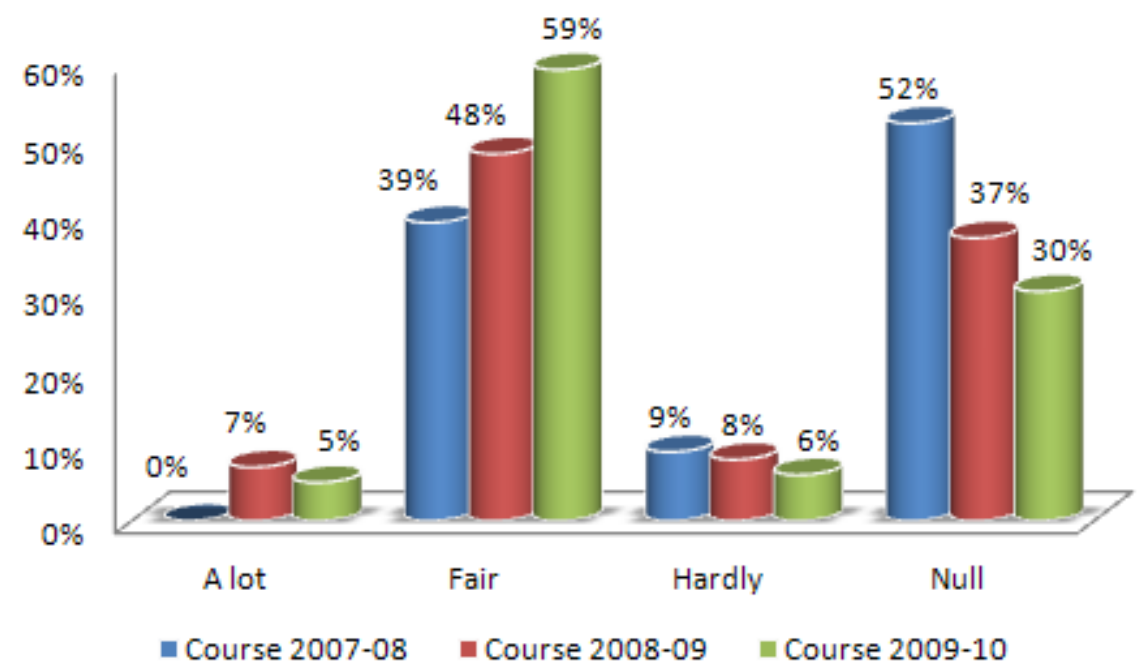

Fig. 1. Students' opinion about the degree of satisfaction with the coordination of activities.

Coordination work has promoted the need for having a coordinator for each course as well as the entire degree. Moreover, to achieve a homogeneous student workload we feel that it must be compulsory that the Teaching Guide of the course include the distribution of the activities; hence, there is a need for a tool which allows for the cognition (teachers and students) and the modification (teachers) of activity distribution. In the case presented in this paper we state that "Google Calendar" is an effective tool for performing such coordination. Coordination also entails a greater level of collaboration between departments, enabling teachers to share resources and improve the scheduling of the courses.

\section{TEACHING METHODS USED IN THE DEGREE}

As far as teaching methodologies are concerned, the main objective of the GIDEN was to determine the methodologies being used and assess how they were being developed in order to identify the different activities associated with them. With this objective a teaching methods log card, which was filled out by the teacher of the degree, was established. In this card (see Fig. 2) teachers were to consider the methods that best suited their classroom setting. They also had to identify the activities that best supported these methodologies. The definitions of the teaching methods were based on that of M. de Miguel, [10]. In Fig. 2, the "\%time devoted" column provides information on the total amount of course time in which the methodology was used. The remaining columns indicate the teaching activity applied.

Another important issue was to determine the way in which the activities that supported the methods were being implemented. In additional log cards teachers were thus asked to reflect on this factor (see Fig. 3). In this case "\% time devoted" indicates the percentage of course time devoted to the activity, whereas the "\% assessment" indicated the weight of the activity in the final grade. 


\begin{tabular}{|c|c|c|c|c|c|c|c|c|}
\hline \multirow{3}{*}{$\begin{array}{c}\text { Teaching } \\
\text { Methodologies }\end{array}$} & \multicolumn{7}{|c|}{ Teaching Activities } & \multirow{3}{*}{$\begin{array}{l}\text { \% time } \\
\text { devoted }\end{array}$} \\
\hline & \multirow{2}{*}{$\begin{array}{c}\text { Classroom } \\
\text { lessons }\end{array}$} & \multicolumn{2}{|c|}{ Laboratory Practice } & \multirow{2}{*}{$\begin{array}{c}\text { Teacher } \\
\text { Mentoring }\end{array}$} & \multirow{2}{*}{ Seminars } & \multirow{2}{*}{$\begin{array}{l}\text { Study/ } \\
\text { Work }\end{array}$} & \multirow{2}{*}{ Visits } & \\
\hline & & Instrumental & computer & & & & & \\
\hline \multicolumn{9}{|l|}{$\begin{array}{l}\text { Expositive Class / } \\
\text { Master Class (lecture) }\end{array}$} \\
\hline \multicolumn{9}{|l|}{ Case Study } \\
\hline \multicolumn{9}{|l|}{$\begin{array}{l}\text { Solving Exercises and } \\
\text { Problems }\end{array}$} \\
\hline \multicolumn{9}{|l|}{$\begin{array}{l}\text { Problem Based } \\
\text { Learning }\end{array}$} \\
\hline \multicolumn{9}{|l|}{ Project Based Learning } \\
\hline \multicolumn{9}{|l|}{ Cooperative Learning } \\
\hline \multicolumn{9}{|l|}{ Learning Agreement } \\
\hline $\begin{array}{l}\text { Other (specify by } \\
\text { adding rows) }\end{array}$ & & & & & & & & \\
\hline
\end{tabular}

Fig. 2. Teaching methodologies card: Methodologies vs. teaching activities.

\begin{tabular}{|c|c|c|c|c|c|c|c|c|c|c|c|c|}
\hline \multirow{3}{*}{\multicolumn{2}{|c|}{ Teaching Activities }} & \multicolumn{11}{|c|}{ Implementation modality } \\
\hline & & \multicolumn{3}{|c|}{$\begin{array}{l}\text { Group } \\
\text { size }\end{array}$} & \multicolumn{2}{|c|}{ Attendance } & \multicolumn{2}{|c|}{ Deliverables } & \multicolumn{2}{|c|}{$\begin{array}{l}\text { Oral } \\
\text { Presentation }\end{array}$} & \multirow{2}{*}{$\begin{array}{l}\% \text { time } \\
\text { devoted }\end{array}$} & \multirow{2}{*}{$\begin{array}{l}\% \\
\text { assessment }\end{array}$} \\
\hline & & 1 & G & $\mathrm{T}$ & Yes & $\begin{array}{l}\text { No / } \\
\text { (on-line) }\end{array}$ & Yes & No & Yes & No & & \\
\hline \multicolumn{13}{|l|}{ Lecture } \\
\hline \multirow{2}{*}{ Laboratory } & Instrumental & & & & & & & & & & & \\
\hline & Computer & & & & & & & & & & & \\
\hline \multicolumn{13}{|c|}{ Teacher Mentoring } \\
\hline \multicolumn{13}{|c|}{ Seminars } \\
\hline \multicolumn{13}{|c|}{ Autonomous study / work } \\
\hline Visits & & & & & & & & & & & & \\
\hline
\end{tabular}

Note: "I"= Individual, "G"= Group of two students, "T"= Group of three or more students.

Fig. 3. Teaching methodologies card: Implementation modality vs. Teaching activities.

From the data collected from these cards during the three academic years it was found that:

- Before the creation of the GIDEN, its members implemented active learning methods in their classes; they had already changed their method which was formerly based on a knowledge transmission. However, in spite of this change, teachers needed an environment in which they could contemplate and discuss innovation processes.

- A methodological change in a course requires an intense process of reflection, critical analysis and prudence. The GIDEN provided a suitable environment for the type of dialogue and analyses necessary for the introduction of new methods and experiences, and for the promotion of the use of new methods in the degree. In this sense, although lectures and problem solving (which complement each other very well) are still the most widely used methods, there has been an increment in the use of more active methodologies such as problem-based learning, cooperative learning and projectbased learning [7]. It was pointed out that participation in courses on pedagogical innovation played an important role in the introduction of these methods. 
The study of teaching methodologies was rounded off with a survey completed by the students. From these surveys data was obtained on:

- Opinions of students about the teaching methodologies used: To reach this objective, students answered questions related to teaching methods (see Fig. 4). Based on their responses, we have seen that the degree of student satisfaction with the teaching methods was high. It must be pointed out that there is a large number of students that indicate that these methodologies facilitated their learning process during the course.

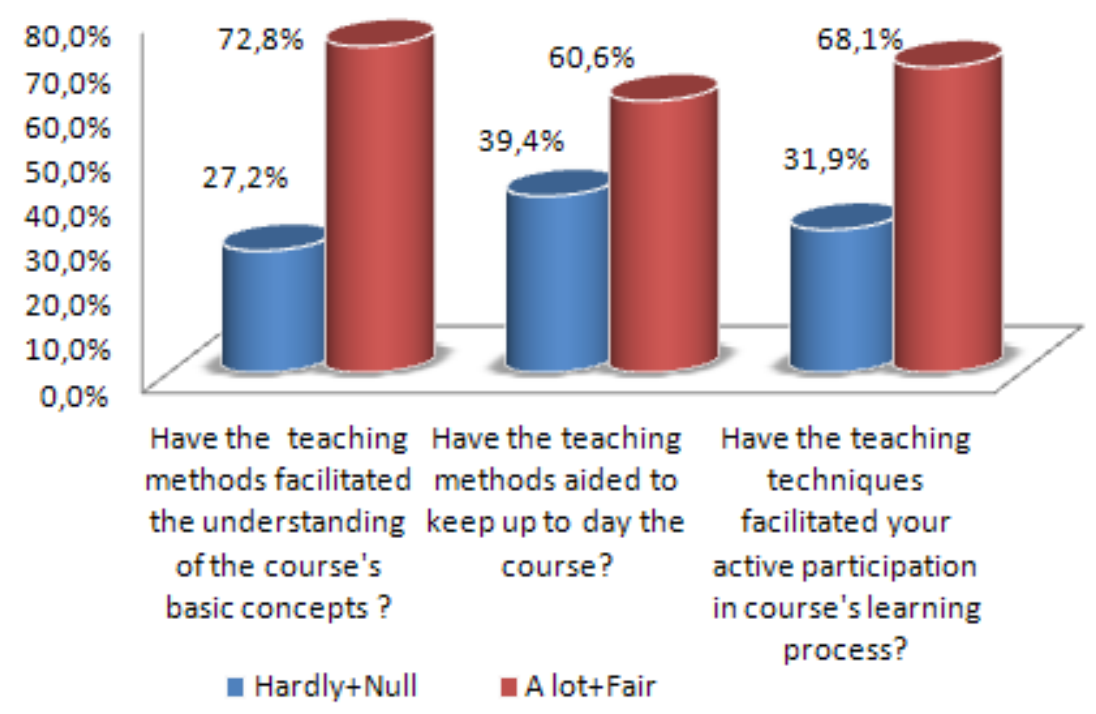

Fig. 4. Degree of satisfaction results with the teaching methodologies used.

- The three methods considered by the students as those which best facilitated their learning and the development of generic skills: The results were sorted based on the kind of course (basic or specific) and the year of the degree (first, second and third year). From the analysis of the data it was deduced that, independently of the nature of the course and academic year, the teaching methods that students felt were best geared towards achieving the learning objectives and the development of the generic skills were: Problem-solving exercises and problem-based learning and lectures. It must be pointed out that in most courses during expositive classes, students actively participated, and in all courses this method was combined with problem-solving exercises. In those courses where group activities were carried out, cooperative learning was considered an excellent methodology for reaching the stipulated teaching objectives.

- The kind of activities considered by students as facilitators of reaching educational objectives and the development of generic skills, were classroom theory lessons (active lessons), work-study and teacher mentoring. In courses with a high emphasis on one on one activities centered on problem-solving exercises, teaching mentoring became less relevant. However, in courses where the theoretical component was very high, teaching mentoring was considered a very effective activity.

- The implementation modalities that the students felt best facilitated the achievement of educational objectives and skill development were: Individual work, work delivery, work group and one on one activity.

Teachers were asked to develop a final report of the course which, once completed, had to include:

- Number of students enrolled in the course.

- Kind of activities and their weight in the final grade.

- Participation in activities and results.

- Difficulties in the development of the activities. 
- $\quad$ Suggestions for improvements.

- Academic results and their relationship with the degree of participation in the activities.

- Connection between the academic results, the number of students enrolled in the course and the number of assessment opportunities used.

The development of this final report helped us to assess the activities, academic results, etc., achieved during the course. This, together with the results from the surveys, provided feedback with which we were able to identify the weaknesses and strengths of the course, as well as the proposals for improvements for the following academic year.

Based on the analysis of the log cards filled out by the teachers, the end of course reports, the academic results and the surveys from the three academic courses, we are able to conclude that:

- The most effective teaching methods in basic level courses are: problem solving exercises and problem-based learning and lectures. A combination of these methods thus seems to be the most appropriate for improving the learning/teaching process in this kind of course.

- In specific courses the following teaching methods have proved to be more effective: problem solving exercises (associated with an expositive lesson), problem-based learning and project-based learning.

- In courses with group activities, a high number of students chose Cooperative Learning as the best teaching method.

- The importance of group activities increases when they are present in numerous courses, making it easier for students and teachers to see the improved results obtained. Furthermore, it must be pointed out that the courses organized by the GIDEN which incorporated work group techniques lead to a reduction in problems typically encountered in this type of activity.

\section{ASSESSMENT TECHNIQUES USED IN THE DEGREE}

One of the GIDEN's main objectives was to identify and analyze assessment criteria in the courses of the degree. To accomplish this, a log card of assessment methods was developed which had to be filled out by the teachers of the degree. In this card (see Fig. 5), teachers were asked to identify the assessment methods used in their respective courses (i.e. assessment activity) according to the definitions given in [10], and their weight in the final activity grade with respect to the teaching method used. In addition, the teachers in question were requested to identify (i.e. provide feedback) for each assessment activity, the weight which corresponded to a given formative assessment $[3,4]$ and the weight, which was merely summative (i.e. part of the course's final grade).

Table 1 summarizes the data collected from the assessment report cards which indicated the percentage of courses in which each evaluation method was used. It also outlines the weight this information carried during the course and in the final test. It can be seen that the objective tests (in question or short-answer format) and extended-response tests (problem solving) and traditional evaluation techniques, are still the most widely used assessment techniques. More modern assessment techniques, such as co-evaluation or self-assessment, still don't carry significant weight in the overall grade. This is essentially due to the fact that they are used in a lot of courses with a more formative (i.e. formative assessment) character. In such courses, the objective is not to provide a grade but rather to develop generic and specific skills. In most courses, the overall weight of the final test is beginning to diminish, giving way to a more desirable environment in which the activities evaluated during the course have greater value and thus favor the student learning process. 


\begin{tabular}{|c|c|c|c|c|c|c|c|c|c|c|c|c|}
\hline \multirow[b]{3}{*}{ Evaluative Activity } & \multicolumn{7}{|c|}{$\begin{array}{c}\text { Percentage in the total score of the } \\
\text { assessment/activity in relation to the teaching } \\
\text { method used }\end{array}$} & & & & & \\
\hline & \multirow{2}{*}{ 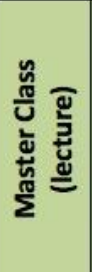 } & \multirow{2}{*}{ 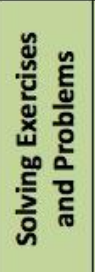 } & \multirow{2}{*}{ 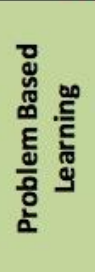 } & \multirow{2}{*}{ 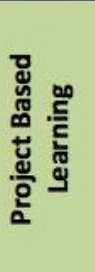 } & \multirow[b]{2}{*}{ 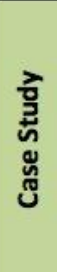 } & \multirow{2}{*}{ 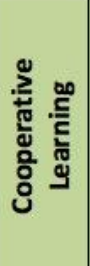 } & \multirow[b]{2}{*}{ 点 } & \multicolumn{5}{|c|}{$\begin{array}{c}\text { Total Percentage in } \\
\text { Rating }\end{array}$} \\
\hline & & & & & & & & 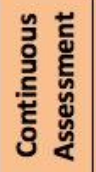 & 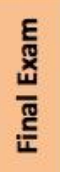 & 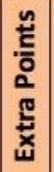 & 密 & 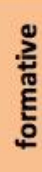 \\
\hline \multicolumn{13}{|l|}{ Objective test } \\
\hline \multicolumn{13}{|l|}{ Short-answer test } \\
\hline \multicolumn{13}{|l|}{ Extended-response test } \\
\hline \multicolumn{13}{|l|}{ Oral test } \\
\hline \multicolumn{13}{|l|}{ works and projects } \\
\hline \multicolumn{13}{|l|}{ lab reports } \\
\hline \multicolumn{13}{|l|}{$\begin{array}{l}\text { Performance tests of real and/or } \\
\text { simulated tasks }\end{array}$} \\
\hline \multicolumn{13}{|l|}{ Self Assessment } \\
\hline \multicolumn{13}{|l|}{ Coevaluation } \\
\hline \multicolumn{13}{|l|}{ Attitude scale } \\
\hline \multicolumn{13}{|l|}{ Observation Techniques } \\
\hline \multicolumn{13}{|l|}{ Portfolio } \\
\hline TOTAL & & & & & & & & & & & & \\
\hline
\end{tabular}

Fig. 5. Assessment methods card.

Table 1. Analysis summary of the assessment methods card.

\begin{tabular}{|c|c|c|c|}
\hline Assessment Techniques & \% courses & \% continuous evaluation & \% in final test \\
\hline Objective test & $64 \%$ & $0 \%$ a $6 \%$ & $50 \%$ a $80 \%$ \\
\hline Short-answer test & $82 \%$ & $4 \%$ a $30 \%$ & $10 \%$ a $45 \%$ \\
\hline Extended-response test & $55 \%$ & $8 \%$ a $40 \%$ & $35 \%$ a $70 \%$ \\
\hline Oral test & $46 \%$ & $4 \%$ a $15 \%$ & $0 \%$ \\
\hline Work and projects & $82 \%$ & $5 \%$ a $45 \%$ & $0 \%$ \\
\hline Lab reports & $64 \%$ & $4 \%$ a $20 \%$ & $0 \%$ \\
\hline Performance tests of real and/or simulated & $18 \%$ & $0 \%$ a $5 \%$ & $0 \%$ \\
\hline tasks & $9 \%$ & $0 \%$ & $0 \%$ \\
\hline Colf Assessment & $27 \%$ & $5 \%$ a $7,5 \%$ & $0 \%$ \\
\hline Observation techniques & $27 \%$ & $5 \%$ a $10 \%$ & $0 \%$ \\
\hline Portfolio & $9 \%$ & $0 \%$ a $5 \%$ & $15 \%$ \\
\hline
\end{tabular}


Another instrument that helped us to carry out the assessment methods study was a survey filled out by students in which they were asked to:

- Indicate the degree of satisfaction with the assessment methods. Fig. 6 shows that this factor was viewed highly favorably. Most of the complaints given concerned the time allocated for carrying out the activities/tests. Nevertheless, this expression of discontent diminished significantly in the second and third courses. This fact had to with the disorganization and lack of planning associated with the study. Thereby, it can be concluded that students could indeed benefit from an adjustment period upon incorporating those methodologies which require continuous work. The degree of satisfaction expressed with the overall ratings is related to the following two topics:

1. In workgroup activities, the success of a given activity is related to group members' ability to solve conflicts among them.

2. In all cases, the use of assessment rubrics [7] facilitated the achievement of the formative objectives and the development of competences, being this a very much appreciated tool for clarifying assessment criteria.

- Select the three preferred assessment methods or those which they believe helped them to improve their learning process. The results obtained did not show any preference for a particular method, but nevertheless enable us to conclude that:

1. Students prefer continuous evaluation.

2. Work-group tests establish a sense of responsibility between the members of the group, thus encouraging member commitment upon carrying out the test.

3. They request assessment techniques that could provide them with feedback (formative assessment) $[3,4]$. In this manner, co-evaluation has been shown to be a very good tool for making students aware of their own level and allows for the detection of formative voids. This approach can also develop a high number of competences without entailing a significant increase in teacher workload.

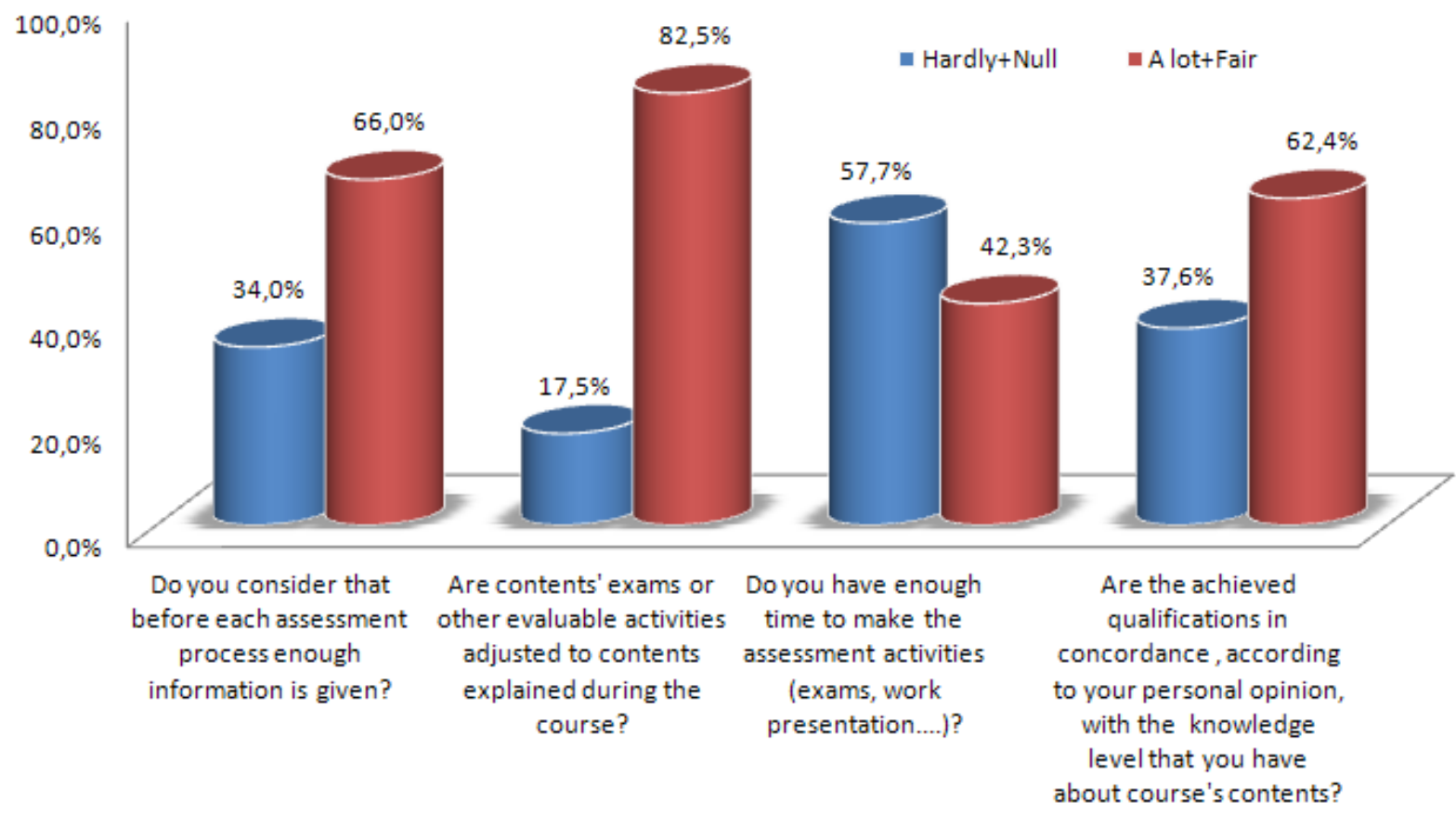

Fig. 6. Results from the evaluation methods survey. 


\section{DEVELOPMENT OF GENERIC COMPETENCES}

As a result of this new educational environment which is centered on the personal and professional development of the student, it is compulsory to define the competence framework within the formative profile of the degrees $[2,10]$. It therefore must not only include the development of specific competences (SC) but also the generic ones (GC). The interest of society lies not only in technical and scientific knowledge, but also it requires that professionals be prepared with generic competences. Furthermore, the competence framework is a requirement in the new degrees that have been adapted to EHEA.

Until now, the educational system was based on the development of the specific competences, hence their development and assessment was not a difficult task for teachers. With generic competences, however, the opposite occurs, making it necessary to select, within the whole framework of instrumental, systemic and personal competences, i.e. those that best suit the professional profile of the degree in question.

As the Electronic and Automatic Industrial Engineering Degree is geared towards a well established professional career, it could be easily thought that the selection of the generic competences being developed would be an easy task and that teachers wouldn't be inconvenienced by adding them to the course curriculum; however, there are some difficulties that have been encountered in this model due to the following reasons [11]:

- The structure of the departments which makes the coordination between teachers from the same degree difficult.

- The teacher credential system which is based primarily on research results within a teacher's area of expertise, whereas teaching has a very low weight in credential system.

- Lack of discrimination between the competences needed for a given professional field (i.e. those developed throughout the degree) and the specific professional competences (required by companies) according to the standards of working professionals.

- $\quad$ The fact that GCs are an integral part of a course's explicit development is frequently overlooked. As they are not necessarily explicit features in and of themselves.

In spite of these difficulties, we are aware of the fact that students can be given a broader vision of their learning process by way of the competence framework, as it provides explicit references to increase their control in the learning processes. The development of GC's could be increased with activities such as workshops, optative courses, etc., but we consider it to be more appropriate that they be introduced in the courses of the degree. Consequently, GIDEN has opted to focus on:

- When and how it is more adequate to incorporate GC's within the courses, and when to make proposals that can integrate the highest number of teachers in a competence-based learning program: The formulation of strategies to develop competencies is not the only important factor, as their distribution in degree courses is also vital. If this analysis is not performed and GCs are distributed taking into account the courses as separate components, it is possible that some competences may not be developed during the degree.

- $\quad$ The course in which it is more appropriate to introduce each GC.

- How GC's can be assessed: Although there are various mechanisms to determine the development of competences, we have considered that continuous assessment is the best strategy to rate the formative activity. A process involving competence assessment cannot be improvised and thus requires a high degree of planning and coherence with respect to the teaching methods, $[7,10]$.

From the work carried out by the GIDEN it can be concluded that the development of GC's is favorable if:

- The developed competence is intrinsic of the course or favors student learning. In such situations students notice greater improvement.

- The development of basic competences starts during the first semester of the first course.

- Teaching methods related to the development of competences are used.

- Activities related to the development of competences are introduced. 
- Information about the competence is provided. To reach this goal, assessment rubrics have proved to be a powerful tool.

- The competence is assessed or at least its development carries a significant weight in the final grade.

- Activities between courses, involving the same groups of students, are planned and coordinated.

Everything mentioned thus far should be taken into account upon establishing a program of competences. There are some competences that are not inherent to the courses, but are essential for passing the course or for achieving the competence objectives of the degree. In this case, the GIDEN proposed that they be assessed within the competence program without carrying a specific weight in terms of the overall student grade but rather with their evaluation appearing in the Degree Supplement.

\section{INNOVATION PROCESSES EVALUATION}

GIDEN's members found it necessary to establish an assessment mechanism for introducing new teaching methodologies in which the impact of the experiences carried out could be measured. The importance of teaching innovation lies in their contribution to the improvement of the learning process [12]. The problem is; how can such an impact be measured? In most situations this is done taking into account the academic results. However, this does not measure aspects such as; teacher and student work motivation, the effect of the innovations on the assessment processes, etc. It should be also taken into account that assessment conditions must favor this process. With these factors in mind it was considered that an external evaluation performed by experts in the area should be carried out. This is a desirable scenario, although difficult to put into practice. In our case, the realization of this external assessment entailed an enriching experience. However, we believe that, from a practical point of view, the assessment of these processes should be developed by teachers (namely course or degree coordinators), who are not directly involved in the learning process.

The experience of the GIDEN has shown that the tools and indicators provided in Table 2, all of them carried out at the end of the academic period, were effective in performing an internal evaluation of the experiences. From our standpoint, on presenting these tools, we have shown the requirements that a quality evaluation should satisfy. The presented process is an excellent feedback mechanism for making decisions about the improvements of the innovation processes.

\section{CONCLUSIONS}

In this paper we have presented the main conclusions obtained after three years of GIDEN's work. One of the key aspects which has made the work of this study feasible, including the proposal of the conclusions presented, was the cooperative work ethic carried out among teachers and students. Collaboration in teaching activity among teachers of the same degree (in research activity this has been successfully achieved) is of great importance as well as necessity. The development of a high quality learning/teaching process depends, among other factors, on the existence of a common educational framework which entails collaboration between teachers of the same degree. In GIDEN the cooperative work developed by the teachers has been proved to be effective in facilitating:

- Vertical and horizontal activity coordination.

- The incorporation of teaching innovations (methodologies and evaluation techniques) in the courses.

- Reflection on the teaching activity which favors continuous improvement.

- The development of competence-based learning.

- The motivation of teachers to improve their activity. 
Table 2. Tools and indicators for measuring the quality of teaching innovations activity.

\begin{tabular}{|c|c|}
\hline Tools & Indicators \\
\hline Teacher's report & $\begin{array}{l}\text { - Description of innovation activity. } \\
\text { - } \text { Evaluation of the effort and dedication of students and teachers during the activity. } \\
\text { - } \text { Differences between the initial proposal and the final proposal. } \\
\text { - } \text { Activities and participation from the students' part. } \\
\text { - } \text { Achievement of the formative objectives and/or development of competences } \\
\text { - } \text { Detection of strengths and weaknesses, and provision of improvement guides. } \\
\text { - } \quad \text { Academic results and their relation with the participation of students in the activities. } \\
\text { - } \quad \text { Evaluation and satisfaction with the innovation process. }\end{array}$ \\
\hline $\begin{array}{l}\text { Opinion survey } \\
\text { from students }\end{array}$ & $\begin{array}{l}\text { - Evaluation of innovation development: Information received effort and time } \\
\text { consumed. } \\
\text { - Evaluation of the relationship between achievements, effort and devoted time. } \\
\text { - Learning objectives evaluation. } \\
\text { - Innovation evaluation: organization, work methodology, materials, etc. } \\
\text { - Identification of key innovation elements that should be improved and proposals for } \\
\text { - } \text { modifications. } \\
\text { Degree of satisfaction with the innovation activity. }\end{array}$ \\
\hline $\begin{array}{l}\text { Focus Group with } \\
\text { students } \\
\text { (6 to } 10 \\
\text { students) }\end{array}$ & $\begin{array}{l}\text { - Opinion survey review. Queries about different innovation elements. } \\
\text { - General questions about other innovation aspects: Did you follow the complementary } \\
\text { activities in Moodle? Were they useful? Has this new teaching method improved your } \\
\text { learning?, etc. } \\
\text { - What should be improved? }\end{array}$ \\
\hline
\end{tabular}

As a result of cooperative work of a group of highly-motivated teachers, the following results were attained:

- Improvement in activity coordination and provision of tools to facilitate this task.

- Adaptation of the teaching methods and evaluation techniques to the teaching-learning process within the framework of the degree.

- Shifting of the educational paradigm from a scheme based on knowledge transmission towards one that ensures student competence in the professional world.

- Establishment of the generic competence definitions which were used in the degree in Electronic and Automatic Industrial Engineering of the UVa.

- Study of the effects of the activities in formative objective achievement and in the level of development of the generic competences. This resulted in the formulation of a series of activities that, through slight modifications if required, can be implemented in different courses to reach the learning objectives and the development of generic competences.

- Elaboration and discussion of evaluation rubrics from the activities.

- Improvement of the materials given to students.

- Introduction of an e-learning platform (Moodle) in some courses of the degree as a complement to the classroom activities.

- Development of the Teaching Guide Courses (TGC) format: From the beginning the GIDEN saw the need for establishing a process which would precisely allow students to become familiar with the specific objectives of the courses of the degree which, in turn, involved an improvement in the formulation of the same. For this reason a TGC format was used [13]. In this sense it was not the piece of paper given the first day of the course that indicated the different topics covered, but rather a detailed layout of the course in which the specific objectives take on an important role. 
- Improvement in the attendance and participation in the classroom activities as well as in the teacher mentoring sessions. This has resulted in a reduction in the number of students who drop out of the course, and an increase in academic performance.

To conclude this paper we would like to point that despite being aware of the resultant enhancements in teaching innovation, it is noteworthy that they gave rise to numerous difficulties such as the low ranking of teaching vs. research activity. This is due to the fact that the most important obstacles are those rooted in many years of routine and unreflective teaching.

\section{ACKNOWLEDGEMENTS}

The authors of this paper would like to thank the teachers who participated in the GIDEN and the students of the degree for their collaboration with the group. Their opinions have no doubt helped us to improve our teaching activity. We would also like to thank the Vicerrectorado de Docencia at the UVa for allowing us to coordinate projects GID2007/13, GID2008 / 2 and GID2009/27 within the Plan of Educational Innovation in the Framework of the EHEA established by UVa.

\section{REFERENCES}

1 J. R. Lohmann; H. A. Rollins and J. J. Hoey, Defining, developing and assessing global competence in engineers, European Journal of Engineering Education, Vol 31(1), 2006, pp. 119-131.

2 R. E. Terry; J. N. Harb; W. C. Hecker and W. V. Wilding, Definition of Student Competencies and Development of an Educational Plan to Assess Master Level, International Journal of Engineering Education, Vol 18(2), 2002, pp. 225-235.

3 N. Pachler; C. Daly; Y. Mor and H. Mellar. Formative e-assessment: Practitioner cases, Elsevier: Computers \& Education, Vol 54(3), 2010, pp. 715-721.

4 W. Tzu-Hua, Web-based quiz-game-like formative assessment: Development and evaluation. Elsevier: Computers \& Education, Vol 51(3), 2008, pp. 1247-1263.

5 F. K. Fink and F. Kjaersdam, UICEE Centre for Problem Based Learning (UCPBL), Journal for Global Engineering Education, Vol 8(1), 2004, pp. 65-70.

6 R. M. Felder and R. Brent, Cooperative Learning in Technical Courses: Procedures: Pitfalls and Payoffs, 1994, http://cgiss.boisestate.edu/ billc/Teaching/Tips/Cooperative learning felder 1994.pdf, [Accessed 8th May 2011].

7 F. Martínez; L. C. Herrero and S. De Pablo, Project-Based Learning and Rubrics in the Teaching of Power Supplies and Photovoltaic Electricity, IEEE Transactions on Education, Vol 54(1), 2011, pp. 87-96.

8 M. González and L. C. Herrero, GIDEN, Grupo de estudio para la mejora Docente, Cadiz, 2008, XVI CUIEET.

9 T. Feddern-Bekcan, Google calendar, Journal of the Medical Library Association, Vol 96(4), 2008, pp. 394395.

10 M. de Miguel (Coord.), Metodologías de enseñanza y aprendizaje para el desarrollo de competencias: Orientaciones para el profesorado universitario ante el EEES, Alianza Editorial, Madrid, 2006.

11 J. Rué, Enseñar en la Universidad. El EEES como reto para la Educación Superior, Narcea, Madrid, 2007. 
12 T. Mauri, C. Coll and J. Onrubia. Quality evaluation of innovative teaching in higher education. A constructivist perspective, Revista de Docencia Universitaria, Vol 1(1), 2007, http://www.um.es/ead/Red_U/1/mauri.pdf, [Accessed 25th July 2011]

13 M A. Martín (Coord.), Adaptación de la E.U. Politécnica de la Universidad de Valladolid el EEES con la participación de las Escuelas Superiores de Valladolid, Zamora y Burgos. Proyecto de Innovación Docente UV23/06, 2007.

Citation: L C Herrero, F Pardo, M L Fernando, M L González, reflections and conclusions on the work developed by the group of teaching innovation in electronics at the university of Valladolid, Journal of Technology and

Science Education, JOTSE, Vol: 1 (2), 2011, pp 3-15. ISSN: 2013-6374; DOI: 10.3926/jotse.2011.21 